\title{
MENTAL TOUGHNESS AND MENTAL HEALTH PROBLEMS IN DOCTORS: A MEDIATING ROLE OF EMOTION REGULATION
}

\section{Saba Aslam ${ }^{\otimes \prime}$, Sadia Saleem', Zahid Mahmood'}

\begin{abstract}
OBJECTIVES: To find out the relationship of mental toughness, emotion regulation, and mental health problems among doctors and to identify the mediating role of emotion regulation between mental toughness and mental health problems among doctors.

METHODS: This cross-sectional study was conducted from February to September 2019. Two hundred medical doctors ( 100 house officers \& 100 postgraduates including 50 males and 50 females in each group) working in five government hospitals were selected through stratified sampling technique. The participants were given Mental Toughness Scale (MTS), Emotion Regulation Scale (ERS) and Depression Anxiety Stress Scale (DASS-2I). Correlation and mediation analysis were carried out to find out the relationship and mediating role among all variables.

RESULTS: Age of 200 doctors ranged from 22 to 36 years with mean age of $26.17 \pm 1.83$ years. Mental toughness was found to have negative correlation with emotion dysregulation $\left(-.3 I^{* *}\right)$ and mental health problems $(-.34 * *)$ while had positive correlation with emotion regulation (.43). Mediation analysis highlighted that MTS was no longer the predictor of mental health problems after the effect of mediator as the indirect effect was $(b=-.29, S E=.05)$ and direct effect was $(b=-.35, S E=.05)$. The value of $c$ prime indicated the partial mediating effect of emotion regulation between mental toughness and mental health problems among doctors.
\end{abstract}

CONCLUSION: Emotion regulation and mental toughness both work as a protective factor for mental health problems among doctors. Emotion regulation was working as a positive factor with the combination of mental toughness against mental health problems among doctors.

KEY WORDS: Emotional Regulation (MeSH); Mental Health (MeSH); Hospitals (MeSH); Depression (MeSH); Resilience, Pscychological (MeSH).

THIS ARTICLE MAY BE CITED AS: Aslam S, Saleem S, Mahmood Z. Mental toughness and mental health problems in doctors: a mediating role of emotion regulation. Khyber Med Univ J 202I;I3(I):I0-14. DOI: https://doi.org/l0.35845/kmuj.202I.19923.

\section{INTRODUCTION}

W orld has witnessed a remarkable improvement in medical field in terms of medication and the quality of patient care.' Doctors are the backbone of healthcare system and since it is among the most stressful professions. ${ }^{2}$ The doctors tend to faces many stressors as workload, emotional burden and violence at workplace, ${ }^{3,4}$ which may lead to different mental health concerns. ${ }^{5}$ Prolonged occupational stress among doctors leads towards different psychopathologies as depression, suicidal ideation, sleep deprivation, emotional exhaustion \& burnout. ${ }^{6.8}$ These mental health problems impair the professional, personal, social and emotional functioning of the doctors. ${ }^{9}$

Positive psychology focuses on the strength-based model. ${ }^{10}$ Stress at workplace has many long term consequences affects the mental health, but every person has different impact of the same situation, so reaction varies, one in six people are suffering from mental illnesses." Among many other factors, mental toughness is one such factor
I: School of Professional Psychology, Institute of Clinical Psychology, University of Management and Technology, Lahore, Pakistan

Email凶: s2018166006@umt.edu.pk Contact \#: +92-331-2651979

Date Submitted: December 04, 2019

Date Revised: March 10, 2021

Date Accepted: March II, 202।

which may works as a protective factor for different psychopathologies. Mental toughness has been defined as the personality factor which focuses on the dealing of the people with the challenges and stressors of life irrespective of the prevailing circumstances. ${ }^{12}$ Mental toughness has been primarily studied with sports and athletes, ${ }^{13}$ interchangeably used with resilience, grit, hardiness ${ }^{14}$ and with other psychological constructs. ${ }^{15}$ Resilience have been studied as a positive construct to bounce back from stressful situations while mental toughness is the ability of the person to face stressors and challenges. ${ }^{13}$ Grit helps to motivate the person for long term goals and to pursue them. Hardiness works as a personality trait but it remains same throughout the life while mental toughness is not stable. ${ }^{16}$

Mental Health is the state of emotional and psychological well being, individual's ability to use his cognitive and emotional capabilities for proper functioning. Emotion regulation is the capacity of the person to manage one's own emotional responses, to maintain and handling the emotions. ${ }^{17}$ Emotions are regulated in both ways, how the person feels that emotions and how the emotion helps in the specific situation. Sometimes the emotions control actions of the person as emotion dysregulation when the persons are not able to regulate their emotions, inability of the person to use healthy strategies to decrease negative emotions. On the other hand, emotion regulation which works as a protective factor to deal with the stressors helps the person to come out of the negative state of emotions. ${ }^{18}$

As the above literature suggests that doctors performs immensely stressful 
long hour duties, faces many problems as sleep deprivation, frustration which leads towards different mental health concerns but the stigma associated with these issues causing hurdle in taking treatment. ${ }^{7}$ This negligence by doctors can be very damaging for them as well as for their patients. So rational of the study focused on the importance to highlight some protective factors to manage their issues and try to erase the stigma associated with this topic. This will allow the doctors to be the best for themselves, their loved ones and ultimately the people they care for, patients. Our study aimed to identify the mediating role of emotion regulation between mental toughness and mental health problems among doctors providing medical care to patients in various government hospitals of Lahore, Pakistan.

\section{METHODS}

This cross-sectional study was carried out from February 2019 to September 2019 on 200 medical doctors working in five government hospitals of Lahore Pakistan, selected through stratified sampling technique. Two hundred doctors were stratified into house officers $(n=100)$ and postgraduate trainees $(n=100)$ with equal number of male and female doctors in each group (Table I).

Doctors working as house officers and postgraduate, involved in direct provision of care to the patients admitted in hospital were eligible to participate in this study. Doctors who were absent from duty or on leave and doctors working in both government and private hospitals were excluded from study.

Correlation analysis was carried out to find out the relationship between mental toughness, emotion regulation and mental health problems among doctors. To make it comprehensive as mental toughness affects mental health problems either directly or by the emotion regulation among medical doctors, mediation analysis was demonstrated by using Process Software in IBM SPSS version 21. Model defined the causal relationship where $X$ as independent variable (IV) (mental toughness) has a direct causal impact on $Y$ as dependent or outcome variable (DV) [mental health problems] or by $M$ as mediator (emotion regulation).

Mediation model explained that X (IV) has an impact on $M$ (mediator) which has an impact on the $Y(D V)$ as outcome variable. Model explained either the mental toughness as an IV affects mental health problem (DV) directly or through the mediator as emotion regulation. If the mediator $(M)$ totally mediate the relationship between $X$ and $Y$, then $c$ prime ( $\left.c^{\prime}\right)$ should be zero. Model indicated that $c^{\prime}$ should be smaller than $c$ in the first model which means that mediator is partially mediating the effect of $X$ (mental toughness) on $(Y)$ mental health problems. Simple Mediation Analysis was carried out to investigate the mediating role of emotion regulation between mental toughness and mental health problems among doctors.

Institutional ethical committee reviewed the project for any ethical considerations. Medical superintendent of hospitals and head of respective departments granted permission to conduct the study. Purpose of the study was explained, and confidentiality was reassured to the participants.

In light of literature, a demographic proforma was developed in which demographic variables were added for the doctors as age, gender, and designation. Indigenously developed mental toughness scale contained 30 items based on four-point Likert scale was used. Mental toughness scale had three factors named as determination, resilience and optimism as well as sound psychometric properties. ${ }^{19}$ Emotion
Regulation Scale, including 50 items, was used, problems were rated according to their intensity, frequency, and duration on the four-point rating scale. Emotion regulation scale had two factors as (ER-FI) emotion dysregulation and (ER-F2) emotion regulation. ${ }^{20}$ Depression Anxiety Stress Scale (DASS) short form was used to check the mental health problems among doctors included 21 items. Participants had to rate each item on the level of severity of problem on four point rating scale. ${ }^{21}$

\section{RESULTS}

Research study was conducted on doctors to see their mental toughness, emotion regulation and mental health problems. Out of 200 doctors, 100 were males and 100 were females. Age ranged from 22 to 36 years with mean age of $26.17 \pm 1.83$ years.

Table II depicted high correlation of three scales as mental toughness, emotion regulation and mental health problems among doctors. Results indicated that mental toughness had positive correlation with emotion regulation (ER-F2) while negative correlation with emotion dysregulation (ER-FI) and mental health problems (DASS-Total). Emotion dysregulation was found to have positive relationship with mental health problems.

\section{Mediation Analysis}

It was found through correlation analysis that mental toughness had positive relationship with emotion regulation while had negative relationship with emotion dysregulation and mental health problems. To make it more comprehensive as mental toughness affects mental health problems either directly or by the emotion regulation among medical doctors, mediation analysis was carried out.

Results of the study indicated that

TABLE I: DESIGNATION AND GENDER DISTRIBUTION OF STUDY PARTICIPANTS

\begin{tabular}{|l|c|c|c|c|c|c|}
\hline \multirow{3}{*}{ Gender } & \multicolumn{6}{|c|}{ Designation } \\
\cline { 2 - 7 } & Post-graduate Trainees $(\mathbf{n}=\mathbf{1 0 0})$ & \multicolumn{2}{c|}{ House Officer $(\mathbf{n}=100)$} & \multicolumn{2}{c|}{ Total $(\mathbf{n}=\mathbf{2 0 0})$} \\
\cline { 2 - 7 } & Frequency & Percentage & Frequency & Percentage & Frequency & Percentage \\
\hline Male & 50 & 50 & 50 & 50 & 100 & 50 \\
\hline Female & 50 & 50 & 50 & 50 & 100 & 50 \\
\hline Total & 100 & 100 & 100 & 100 & 200 & 100 \\
\hline
\end{tabular}




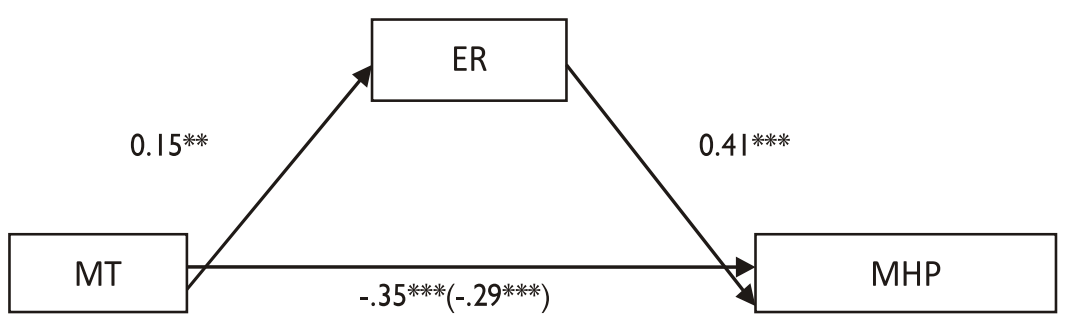

Figure I: Simple Mediation Analysis Model (MHP = Mental Health Problems, $M T=$ Mental Toughness, ER=Emotion Regulation mental toughness was a significant predictor of emotion regulation as $b$ $=0.15$, SE $=0.05, p<0.05$ and the emotion regulation was the significant predictor of mental health problems $(\mathrm{MHP})$ as $b=0.4 \mathrm{I}, \mathrm{SE}=0.06 \mathrm{p}<0.05$ (figure I). Important finding of the study highlighted that emotion regulation was toughness on mental health problems as the indirect effect $b=-0.29, \mathrm{SE}=0.05$, as compared to the direct effect of $b=$ effect of emotion regulation was smaller than direct effect of mental toughness on mental health problems, so these results support the mediational hypothesis. Emotion regulation was found to have partially mediating the relationship between mental toughness and mental health problems among doctors.

\section{DISCUSSION} branches in psychology to emerge, focusing on discovering those factors which helps to promote mental health. ${ }^{18}$ Current study suggested that mental toughness has a strong positive relationship with emotion regulation, an inverse relationship with emotion dysregulation and mental health problems. To see more comprehensive view of the study health problems either directly or by the emotion regulation, mediation analysis was carried out. Findings of the current research suggested that MTSpartially mediating the effect of mental 0.35 , SE $=0.05$. The partial mediating

Positive psychology is one of the latest as mental toughness affects mental
FI (Determination) and F2 (Resilience) were found to be the protective factors against mental health issues among doctors and that ER-FI (Emotion dysregulation) was found to be the risk factor for mental health issues. Findings of the study depicted that emotion regulation can be the protective factor for mental health concerns among doctors as well as emotion regulation was partially mediating the relationship between mental toughness and mental health problems among doctors so it is very important to highlight these protective factors as mental toughness and emotion regulation among doctors.

Prevalence of stress and burnout among doctors have been reported high in Pakistani cultural context which leads towards different mental health concerns.' Usage of unhealthy coping strategies, lack of awareness regarding management of stress and lack of counseling services creates more stress. ${ }^{22}$ It has been seen that doctors performs immensely stressful jobs, issues can arise due to occupational risk factors as the high level of interaction with patients can often be emotionally draining for them. ${ }^{8}$ The factors which creates hurdle while seeking help were the stigma associated with mental health issues and the negligence by the doctors which impacts their own health, career and their patients. ${ }^{6}$ So it was very important to highlight mental health issues among doctors and try to erase the stigma associated with it. The
TABLE II: SUMMARY OF INTERCORELATION, MEANS, STANDARD DEVIATIONS OF THE PARTICIPANTS $(\mathrm{N}=200)$ ON MTS, ERS AND DASS

\begin{tabular}{|l|c|c|c|c|}
\hline & MTS-Total & ER-F I & ER-F2 & DASS-Total \\
\hline MTS-Total & ---- & $-.3 I^{* *}$ & $.43^{* *}$ & $-.34^{* *}$ \\
\hline ER-FI & & ---- & -.04 & $.7 I^{* * *}$ \\
\hline ER-F2 & & & ---- & -.04 \\
\hline DASS-Total & & & & ---- \\
\hline
\end{tabular}

importance have been given to the positive factors which helps to prevent mental health issues as mental toughness, resilience, social support and emotion regulation plays a vital role. 23,24 The current findings of the study revealed that emotion dysregulation was found to be risk factor for mental health concern among doctors which were found to be the consistent findings from previous literature. ${ }^{25}$ Emotion regulation has been studied in literature to work as a protective factor against mental health issues ${ }^{26}$ while the current study explored the combination of mental toughness and emotion regulation against mental health issues. The important findings suggested that mental toughness and emotion regulation both works as a protective factor for mental health concerns among doctors which were found to be unique findings of the study.

The importance of emotion regulation for mental health of doctors have been highlighted so the awareness for mental health need to be increase. There is a dire need to work on management of mental health concerns among doctors. Mental toughness plays a key role for the prevention of mental health among doctors, so it is important to work on mental toughness and resilience among doctors. The study will help to find out ways to plan management strategies for doctors and to work on prevention of mental health. Limitations of the study included that the research was conducted only in government hospitals so it can't be generalized to private hospitals. Another limitation was the comparison of married and unmarried doctors could not be conducted so it is important to study in this dimension too.

\section{CONCLUSION}

Mental toughness and emotion regulation work as protective factors against mental health problems for doctors. Mental toughness was found to have the significant positive relationship with emotion regulation, the increased in mental toughness and emotion regulation among doctors leads towards low mental health issues among them. Findings of the study indicated the importance of emotion regulation and mental toughness for the 
prevention of mental health issues among doctors. These findings can further use as a base for counseling and preventing medical professionals from different mental health concerns. Further study can be conducted with the comparison of government and private institutes as well as with married and unmarried doctors.

\section{REFERENCES}

I. Khalid F, Abbasi A. Challenges faced by Pakistani healthcare system: clinician's perspective. J Coll Physicians Surg 2018;28(I2):89990I. DOI: I0.2927I/jcpsp.2018.I2. 899.

2. Jowett M, Brunal MP, Flores G, Cylus J. Spending targets for health: no magic number, health financing working paper, World Health Organization. 2016; WHO reference number: WHO/HIS/HGF/HF Working Paper/: I6(I).

3. Cox E. Violence in the healthcare workplace. U.S. News Health. 2017.

4. Gohil RK, Singh PK, Saxena N, Patel G. Work place violence against resident doctors of a tertiary care hospital in Delhi, India. Int Surg J 2019; 6(3): 975-98।. DOI: I0.18203/ 2349-2902.isj20190834.

5. Akbar AN. Quality versus quantity: Nurses workload and patient's safety. J Pioneering Med Sci 2016; 6(70). DOI: I0.3390/admsci70I0007.

6. Gawande AV, Barnwal RK, Narlawar UW. Psychological stress among postgraduate medical resident doctors: A cross-sectional study in a tertiary care hospital in Central India. Int J Med Sci Public Health 2019;8(4):275-9.

7. Kalmbach DA, Fang Y, Arnedt JT, Cochran AL, Deldin PJ. Effects of sleep, physical activity, and shift work on daily mood: a prospective mobile monitoring study of medical interns. J Gen Intern Med 2018; 33:9|4-920. DOI: $10.1007 /$ sl 16 06-018-4373-2.

8. Mian A, Kim D, Chen D, Ward WL Medical student and resident burnout: A review of causes, effects, and prevention. J Fam Med Dis Prev 2018; 4:094. DOI:10.23937/2469. 5793/1510094.

9. Kumar M, Verma M, Das T, Pardeshi G, Kishore J, Padmanandan A. A study of workplace violence experienced by doctors and associated risk factors in a tertiary care hospital of South Delhi, India. J Clin Diag Res 2016; 10 (I I):LC06-LCIO. DOI: 10.7860/ JCDR/20 I6/22306.8895.

10. Williams N, Horrells L, Edmiston D, Brady M. The impact of positive psychology on higher education. The William \& Mary Educational Review 20।8;5(I):83-94.

I I. Jiang Y, Guan YJ, Dai DW, Huang W, Huang ZY. Prevalence of stress and its determinants among residents enrolled in China Standardized Training Program for Resident Doctor (C-STRD) program. A crosssectional study. PLoS One 2019 Jan 7;|14(I):e0207258. DOI: 10.137I/ journal.pone.0207258.

12. Akpinar S, Akpinar O. The relationship with the personality and mental toughness at athletes. J Inter Soc Res 20। 8 ; I (6I): I252-5.

13. Arthur CA, Fitzwater J, Hardy L, Beattie S, Bell J. Development and validation of a military training mental toughness inventory. Mil Psycol 20I5;27(4):232-4I. DOI: 10.1037/ mil0000074.

14. Anderson C, Turner AC, Heath RD, Payne CM. On the meaning of grit and hope and fate control and alienation and locus of control and self-efficacy and effort optimism. Urban Rev 2016; 48(2): 198-219. DOI: |0.1007/s | |256-0|6-035I-3.

15. Delaney PF, Goldman JA, King JS, Nelson GRO. Mental toughness, reinforcement sensitivity theory, and the five-factor model: Personality and directed forgetting. Psychology 2015;83:180-4. DOI: 10.1016/ J.PAID.2015.04.020.

16. Kelly DR, Matthews MD, Bartone PT. Grit and hardiness as predictors of performance among west point cadets. Mil Psychol 2014;26(4): 327-42. DOI: I0. 1037/mil0000050.
17. Verzeletti C, Zammuner VL, Galli C, Agnoli, S. Emotion regulation strategies and psychosocial wellbeing in adolescence. Cogent Psychol 2016;3(I):I19-294. DOI: 10.1080/ 23311908.2016 .1199294$.

18. Lin DT, Liebert CA, Tran J, Lau JN, Salles A. Emotional intelligence as a predictor of resident wellbeing. J Am Coll Surg 2016 Aug;223(2):352-8. DOI: 10.1016/j.jamcollsurg.2016.04. 044 .

19. Aslam S, Saleem S, Mahmood Z. The development of a mental toughness scale for doctors: A psychometric study. J Liaqat Univ Med Health Sci 2019; I8(3): 214-8. DOI: 10.22442/ jlumhs. 191830630.

20. Daurani S. Unpublished Development of Scale Doctoral Thesis. Institute of Clinical Psychology, University of Management and Technology Lahore Pakistan. 2016.

2I. Henry JD, Crawford JR. The shortform version of the Depression Anxiety Stress Scales (DASS-2I): construct validity and normative data in a large non-clinical sample. $\mathrm{Br} \mathrm{J}$ Clin Psychol 2005;44(2):227-39. DOI: I0.1348/0 I 4466505X29657.

22. Jamal Y, Niloferfarooqi Y. Professional life stress and coping strategies used by house job doctors. Ethno Med 2016;10(2):132-9. DOI: 10.1080/ 09735070.20I6.II90548I.

23. Ibrahim TAS. Association between depression, anxiety, stress, social support, resilience and internet addiction: $A$ structural equation modeling. Malays Online J Educ Technol 2019;3(7):I-I2. DOI: I0.17220/mojet.2019.03.00I.

24. Kalinin R, Balazsi R, Pentek I, Duica S, Hanțiu L. Relationship between competitive anxiety and mental toughness: a latent regression analysis. Health Sports Rehab Med $2019 ; 2(20): 70-4$. DOI: 10.26659/pm3.2019.20.2.70.

25. Young KS, Sandman CF, Craske MG. Positive and negative emotion regulation in adolescence: links to anxiety and depression. Brain Sci 2019;9(76):I-20. DOI: 10.3390/ 
brainsci9040076.

26. Saleem S, Khan IQ, Saleem T. Anxiety and emotional regulation; anxiety and emotional regulation among pupils of a state-owned medical institution: a gender perspective. Profess Med J 2019;

26(5):734-4I. DOI: 10.29309/ TPMJ/2019.26.05.3469.

\section{AUTHOR'S CONTRIBUTION}

Following authors have made substantial contributions to the manuscript as under:

SA: Conception and study design, acquisition of data, drafting the manuscript, critical review, approval of the final version to be published

SS: Acquisition of data, drafting the manuscript, approval of the final version to be published

MZ: Analysis and interpretation of data, drafting the manuscript, approval of the final version to be published

Authors agree to be accountable for all aspects of the work in ensuring that questions related to the accuracy or integrity of any part of the work are appropriately investigated and resolved.

\section{CONFLICT OF INTEREST}

Authors declared no conflict of interest GRANT SUPPORT AND FINANCIAL DISCLOSURE

Authors have declared no specific grant for this research from any funding agency in the public, commercial or not-for-profit sectors

\section{DATA SHARING STATEMENT}

The data that support the findings of this study are available on request from the corresponding author. The data are not publicly available due to privacy or ethical restrictions.

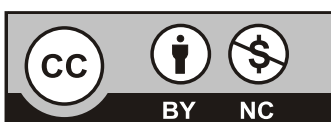

This is an Open Access article distributed under the terms of the Creative Commons Attribution-Non Commercial 2.0 Generic License.

KMUJ web address: www.kmuj.kmu.edu.pk

Email address: kmuj@kmu.edu.pk 